\title{
Effect of Preoperative Anxiolysis on Postoperative Pain Response in Patients Undergoing Elective Lower Limb Major Orthopaedic Surgeries.
}

\author{
Dr. Felicia Dele Asudo ${ }^{1}$, Dr Collins Uzochukwu Enuh ${ }^{2 *}$, Prof. Charles Osalumese Imarengiaye ${ }^{3}$ \\ ${ }^{1}$ Consultant Anaesthetist, Senior Lecturer Department of Anaesthesia University of Abuja Teaching Hospital/ College of Health Sciences University of \\ Abuja Gwagwalada F.C.T Abuja \\ ${ }^{2}$ Consultant Anaesthetist Department of Anaesthesia University of Abuja Teaching Hospital Gwagwalada F.C.T Abuja \\ ${ }^{3}$ Professor of Anaesthesia Department of Anaesthesia University of Benin Teaching Hospital/University of Benin Benin-City, Edo State
}

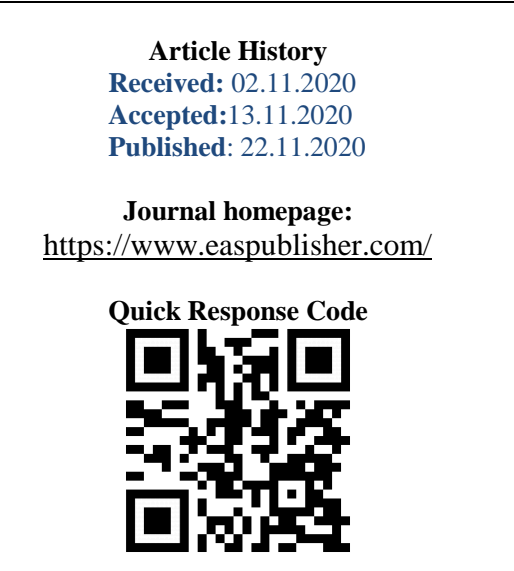

\begin{abstract}
Anxiety is the commonest anticipated problem of patients during the perioperative period. Preoperative anxiety can produce poor postoperative outcome and make the management and control of postoperative pain more difficult. Studies have demonstrated a strong relationship between anxiety and pain. Anxiety leads to elevated pain, likewise pain results in an increased level of anxiety. Therefore, it can be postulated that reducing the amount of anxiety experienced preoperatively with an anxiolytic will reduce the burden of pain experienced by patients postoperatively. This study assessed the clinical effect of preoperative anxiolysis with Lorazepam on postoperative pain perception in patients undergoing elective lower limb major orthopaedic surgeries under combined spinal epidural (CSE) anaesthesia. This was a prospective study of 122 patients who presented for surgeries at the University of Abuja Teaching Hospital, Nigeria. Patients were randomly assigned to receive either Lorazepam $2 \mathrm{mg}(\mathrm{n}=56)$ or placebo $(n=56)$ the night before surgery and $2 \mathrm{~h}$ before scheduled surgery. Postoperative pain scores, analgesic requirements and satisfaction with pain control were evaluated during the first $24 \mathrm{~h}$ following surgery. We found that patients who received Lorazepam reported a significantly lower pain score than placebo group during the first $12 \mathrm{~h}(\mathrm{p}=$ 0.031 ) while morphine requirement was significantly greater in the placebo group than Lorazepam group $(8.20 \pm 1.91 \mathrm{mg}$ vs $14.8 \pm 2.10 \mathrm{mg} ; \mathrm{p}=0.036)$ and patients treated with anxiolytics showed a greater satisfaction with pain relief $(\mathrm{p}=0.0185)$. In summary, preoperative Lorazepam produced significant anxiolysis that led to reduced pain, lower analgesic consumption, and better satisfaction but with modest side effects.
\end{abstract}

Keywords:Anxiety, pain, combines spinal epidural, Lorazepam, Bupivacaine, Morphine, Patient- Controlled Epidural Analgesia.

Copyright (C) 2020 The Author(s): This is an open-access article distributed under the terms of the Creative Commons Attribution 4.0 International License (CC BY-NC 4.0) which permits unrestricted use, distribution, and reproduction in any medium for non-commercial use provided the original author and source are credited.

\section{INTRODUCTION}

Anxiety and pain are the commonest feared problems during the perioperative period. Anxiety is characterized by subjective feelings of tension, apprehension, nervousness and worry [1]. It is the most commonly reported stress-related emotion experienced by patients awaiting surgery. About $60-80 \%$ of surgical patients experience substantial anxiety before operation [2]. Preoperative anxiety has been found to correlate with high postoperative anxiety, increased postoperative pain, increased analgesic requirements, prolonged recovery and hospital stay as well as decreased patient satisfaction with perioperative experience [1, 3]. Uncontrolled preoperative anxiety has been implicated as a main contributor to postoperative pain experience [1-6]. Pain is a major perioperative concern for surgical patients. Previous studies indicated that postoperative pain still remains inadequately treated in spite of the advances in the knowledge of pathophysiology of pain and improvement in postoperative pain management [711].Despite the extensive resources used on patientcontrolled analgesia, spinal drug delivery methods, coanalgesics, multimodal analgesia, guideline for acute pain management, and implementation of acute pain services, the results, in terms of an improved outcome after major surgery, seem unexpectedly modest [7]. A large proportion of admitted patients still experience moderate to severe postoperative pain. Globally the prevalence of postoperative pain ranges from $50 \%$ to $70 \%$ of postoperative patients [10]. An assessment of 1490 surgical patients in Netherlands revealed that, regardless of the presence of an acute pain protocol, $41 \%$ of inpatients had moderate to severe pain, and in a similar study of 261 children undergoing routine tonsilectomy and adenoidectomy the prevalence of postoperative pain was $86 \%$ [8]. A random sample of 250 adults who had undergone surgical procedures in the United States showed that $80 \%$ of patients had acute 
pain postoperatively and, of these $86 \%$ had moderate to severe pain $[8,9]$. A study of postoperative pain in Nigeria reported that $95 \%$ of postoperative patients experience various degree of postoperative pain[11]. As a result of the inadequacies in postoperative pain management relief, research have recently focused on investigating pharmacologic and psycho-physiologic explanations for the insufficient pain relief as well as inadequate response to analgesic requirements. Current theory and research suggests that pain phenomena is a sensory and emotional experience[5],hence, increased awareness of the importance of psychological factors and intensifying the preoperative treatment will allow more effective intervention to better postoperative pain management. If increased preoperative anxiety is associated with high postoperative anxiety, increased postoperative pain and analgesic requirement [1, 3-5], it can be hypothesized that reducing the amount of preoperative anxiety could reduce these adverse surgical outcomes and improve postoperative care. Various pharmacological and non-pharmacological regimens to reduce preoperative anxiety have been devised $[4,5,12]$. When medication is the treatment of choice to reduce preoperative anxiety, the benzodiazepines (BZD) are the drugs most commonly used [12].

Despite the routine use of BZD or reduction of anxiety before surgery, the effect has been mainly assessed in relation to haemodynamic changes, preoperative anxiety, amnesia and quality of induction of anaesthesia[4].There is limited evidence on the effect of anxiolysis on orthopaedic surgical procedures. Orthopaedic procedures have been found to be a strong predictor for both postoperative pain and increased analgesic consumption. Bone injury is more painful than soft tissue injury, owing to the fact that the periosteum has the lowest pain threshold of the deep somatic structures [13].

This study, therefore assessed the effect of preoperative anxiolysis with Lorazepam on postoperative pain response based on analgesic consumption and pain scores in inpatients undergoing lower extremity major orthopaedic surgeries in our institution.

\section{Material And Methods}

After the approval by the institutional ethical committee and written informed consent was obtained from 112 patients with American Society of Anaesthesiologists (ASA) physical status I or II who are aged 18 and 65 years and scheduled to undergo major orthopaedic lower limb procedures, were enrolled into the randomized, double-blind, placebo-controlled study. Patients with ASA classifications III or IV, contraindication to regional anaesthesia, existing mental impairment, psychiatric disease, overt behavioural impairment or on psycho-tropic drugs; refusal and inability to complete the questionnaire, read or speak
English; emergency surgery and procedures that was converted to general anaesthesia were excluded. Patients that consented to the study were educated on the anxiety and pain evaluations during the preoperative assessment. Each patient completed the forms during the preoperative review for base line anxiety and pain score as well as at several time points after the surgery.

All patients were also taught how to use the patient controlled analgesia (PCA). Anxiety evaluation was done using the State/Trait Anxiety Inventory (STAI)-State questionnaire. The STAI-State (STAI-S) form consists of 20 statements, and answers to these were used to determine a patients' transitory or situational current emotional state. Each of the 20 items is a statement rated in a four-point scale with responses being either 1(not at all), 2(somewhat/mildly so), 3(moderately so), or 4 (very much so). At each measurement subjects circled the number that best described how they felt in general (Appendix I). The overall (total) score for STAI ranges from a minimum of 20 to a maximum of 80 ; STAI scores are commonly classified as no or low anxiety (20 - 37), moderate anxiety (38 - 44) and high anxiety (45 to 80$)$. Regarding the VAS form, the patient marked $(\mathrm{X})$ at a point on a $10 \mathrm{~cm}$ line that corresponded to the intensity of their pain. The scale consist of a $10-\mathrm{cm}$ line, that pictorially represents a continuum between two extremes; no pain (score of 0 ) and worst pain imaginable (score of 10) (Appendix II).

Randomization was performed with opaque sealed envelopes containing randomized numbers belonging to either of the two study groups. In the treatment group, patients received oral Lorazepam $2 \mathrm{mg}$ the night and 2 hours before surgery whereas in placebo group, patients received placebo at the same time. During the usual preanaesthetic visit all patients were reviewed on the ward the night before surgery to provide information to the patient on the perioperative course and the technique of anaesthesia. In the course of the preanaesthetic review, the study was explained to the patient and written informed consent obtained. The psychological testing using the STAI and the VAS pain scoring systems were also explained to the patient at this time. To ensure blinding, every patient was enrolled into a study group by one of the researchers that were not involved in the preoperative assessment, conduct of anaesthesia and record of intraoperative and postoperative outcomes.

Demographic data were gathered from the case notes and patients which included the patients' age as at last birthday, sex, height, ASA classification, preoperative diagnosis and type of surgery. These were recorded on the preformed data collection form (Appendix III). Measurements of arterial blood pressure, pulse rate and self-assessment of the patients' level of anxiety and pain score were obtained for baseline. The relevant laboratory investigations were 
examined (pack cell volume and urinalysis). Electrocardiogram (ECG) and chest radiograph were investigated for patients above 40 and 50years respectively. All patients observed the preoperative fasting guideline and received either oral Lorazepam 2 $\mathrm{mg}$ or placebo at 22.00 hours. On the day of surgery, $2 \mathrm{~h}$ preoperatively, all patient received the same medication that they had the previous night (ie Lorazepam $2 \mathrm{mg}$ or placebo) with a sip of water.

On arrival in the operating theatre all patients had standard monitoring of the pulse rate, non-invasive arterial blood pressure (NIBP), respiratory rate, oxygen saturation $\left(\mathrm{SpO}_{2}\right)$ and ECG using a multiparameter monitor (Texan 007). An intravenous line was secured on the none. Dominant hand with size $16 \mathrm{G}$ or $18 \mathrm{G}$ cannula and patients were co-loaded with $15 \mathrm{ml} / \mathrm{kg}$ of Normal saline solution. All drugs and equipment for general anaesthesia (GA), as well as emergency resuscitation drugs (ephedrine, atropine, and adrenaline) were kept on the table close to the anaesthetic machine. Combined spinal epidural (CSE) technique was performed for all patients in sitting position under aseptic conditions using the midline approach after infiltration with $2 \mathrm{mls}$ of $2 \%$ lignocaine at the L3- L4 or L4 - L5 inter-space. The epidural space was located at the inter-space using a loss- of- resistance technique and a $18 \mathrm{G}$ Tuohy needle. A needle-through-needle technique was used wherein; a $27 \mathrm{G}$ Pencil point spinal needle was introduced into the subarachnoid space. With the puncture of the dura signified by free backward flow of cerebrospinal fluid, $2.5 \mathrm{ml}$ of $0.5 \%$ hyperbaric Bupivacaine was injected via the spinal needle. Immediately after the removal of the spinal needle, a 20-G epidural catheter was threaded into the epidural space and secured in position with a sterile gauze dressing. Patient was immediately placed in supine position with slight head up using a pillow under the head and shoulder and verbal contact was maintained within the first 15 minutes. Pulse rate and blood pressure were recorded at two minute interval for the first 15 minutes and every 10 minutes thereafter, throughout the surgery. Continuous oxygen saturation and ECG were also monitored. Two hours following the spinal injection, the first top-up with $10 \mathrm{ml}$ solution of $0.5 \%$ plain Bupivacaine was injected via the epidural catheter. Additional boluses of $5 \mathrm{ml}$ of the solution was administered if there were signs of inadequate analgesia. A minimum of 30 minutes was maintained between injections. Intraoperative vital signs were measured and recorded after each injection. Hypotension defined as systolic blood pressure less than $90 \mathrm{mmHg}$ or a decrease greater than $20 \%$ from baseline,was treated initially with Normal saline infusion and Ephedrine in aliquots of 3-6mg until blood pressure returns to normal. Bradycardia defined as heart rate less than 50 per minutes, was treated with Atropine $0.3-0.6 \mathrm{mg}$ intravenously. Oxygen at the rate of $4 \mathrm{~L} /$ minutes via nasal prongs was administered whenever $\mathrm{SPO}_{2}$ dropped below 92\%. Transfusion trigger was based on target pack cell volume of $28 \%$. Crystalloid was used to replace blood in the ratio of $3: 1$ respectively until transfusion trigger was reached. Afterward whole blood in the ratio of 1:1 was used to replace blood loss. Intraoperative variables such as the length of surgery and anaesthesia, blood loss, IV fluid use, urine output, blood transfusion, anaesthetic and surgical complications, doses of ephedrine and atropine used were recorded.

At the end of the surgery, the epidural catheter was left in place for continued postoperative analgesia. The PCA device was made available in the recovery room and the instructions on the use of the PCA pump were repeated to the patient after whom the epidural catheter was connected to a PCA device that contains $0.125 \%$ plain bupivacaine and $0.05 \mathrm{mg} / \mathrm{ml}$ of preservative free morphine. This solution was delivered at $4 \mathrm{ml} / \mathrm{h}$ with a Patient Controlled Epidural Analgesia (PCEA) bolus of $0.5 \mathrm{ml}$ and lockout interval of 15 minutes. If patient's pain was unrelieved (VAS greater than 3 ) the PCEA doses were increased by $2 \mathrm{ml}$ and, if it remained unabated, additional increments were added until adequate pain control was achieved. The maximum dose that can be reached was $14 \mathrm{ml} / \mathrm{h}$. From the recovery patient was taken to the ward and PCEA was continued up to $24 \mathrm{~h}$ postoperatively. No other analgesic was offered to the patient at this period. Pain score was recorded 3 hourly postoperatively at $\mathrm{T} 1, \mathrm{~T} 2$, T3, T4, T5, T6, T7, and T8 while anxiety was recorded 6 hourly postoperatively at time A1, A2, A3 and A4. The total analgesic requirement for each of the patient was calculated from the amount of plain bupivacainemorphine solution received through the epidural PCEA for up to 24 hours after surgery. The patient satisfaction with postoperative pain relief was evaluated 24 hours after surgery using a four point scale; $0=$ poor, $1=$ fair, $2=$ good and $3=$ excellent (Appendix IV). STAI and VAS score as well as assessment of patient's satisfaction were evaluated at several points. Patient's blood pressure, $\mathrm{SPO}_{2}$ and respiratory rate were monitored half-hourly.

Data was collected using a structured data collection form (Appendix III) and anaesthetic chart. Patients' age as at last birthday, sex, height of patient in centimeters, comorbid history, surgical diagnosis and procedure, duration of surgery and anaesthesia other intraoperative data were recorded. Measurements of postoperative anxiety and pain at different intervals and analgesia consumption were documented. Demographic data were analyzed using the Statistical Package for Social Science (SPSS) version 20 for window statistical software Summary of statistics were done using means and standard deviations and the results presented in the form of tables, charts, percentages and graphs. Tests of association for continuous variables were done using Student's t-test and Pearson's correlation. A p-value of less than 0.05 was considered statistically significant.

RESULTS AND DISCUSSION 
One hundred and twenty one patients were studied. A total of nine patients were excluded; five did not wish to continue and four were converted to general anaesthesia due to failed epidural anaesthesia. Therefore, 112 subjects were included in the final analysis (anxiolysis 56; placebo 56). Although the patients' demographic characteristics were comparable in the two groups, there was a male preponderance and male-female ratio was significantly higher in the anxiolysis group $(\mathrm{p}=0.029)$ (Table 1$)$. The distribution of the surgical procedures was similar in both groups ( $p$ $>0.05)$. (Table II). Patients' characteristics of intraoperative variables are summarized in table III. The anti-emetic doses of metoclopromide used was significantly greater (60mg vs $0 \mathrm{mg}$ ) in the anxiolysis group, as patients who received Lorazepam had a higher incidence of nausea or vomiting $(\mathrm{p}=0.027)$, (figure 1). This occurred before induction of anaesthesia.

Initial assessment of state anxiety was comparable in both groups at the preoperative period (STAI mean score: placebo $38.1 \pm 3.2$ and anxiolysis $39.2 \pm 3.0, p=0.659)$, (Table IV). The incidence of low, moderate and high preoperative anxiety were $32.1 \%$, $26.8 \%$ and $41.1 \%$ respectively. The mean state anxiety levels, assessed on the State Trait Anxiety Inventory showed a score significantly lower in the Lorazepam group compared to the placebo group at $6 \mathrm{~h}(\mathrm{p}=0.028)$, $12 \mathrm{~h}(\mathrm{p}=0.034)$ and $18 \mathrm{~h}(\mathrm{p}=0.049)$ ( Figure 2$)$. A steady reduction in the postoperative state anxiety over time was also reported in both groups in the first 24 hours.

There was an effect in the treatment group on postoperative pain over time. The Lorazepam group reported a significantly greater difference in selfreported postoperative pain measured at $6 \mathrm{~h}$ (3.8 vs 6.8 ; $\mathrm{p}=0.021)$ and $12 \mathrm{~h}(2.8$ vs $4.6 ; \mathrm{p}=0.031)$. The apparent benefits of anxiolysis was lost by the $18^{\text {th }}$ hour postoperatively ( $\mathrm{p}=0.634$ ) (Figure 3 ). The subgroup with moderate to high state anxiety $6,12,18$ and 24hours after surgery had an incidence of moderate to severe postoperative pain (VAS >3) of $38.5 \%, 33.3 \%, 37.5 \%$ and $28.6 \%$ respectively reported in the anxiolysis group compared to $84.0 \%, 76.1 \%, 72.2 \%$ and $73.9 \%$ in the placebo group.(Table V). Assessment of bupivacaine-morphine consumption showed an effect on the treatment group. The analgesics requirement were significantly greater in the group that received placebo in the first $12 \mathrm{~h}(6 \mathrm{~h} ; \mathrm{p}=0.031$ and $12 \mathrm{~h} ; \mathrm{p}=$ 0.048 ) than in the later postoperative period ( $\mathrm{p}=0.053$ and 0.059) respectively. There was a statistically significant difference in cumulative morphine requirement during the first 24 hours after surgery in the placebo group compared to anxiolysis group (14.8 \pm $1.91 \mathrm{mg}$ vs $8.2 \pm 2.10 \mathrm{mg}, \mathrm{p}=0.036$ ). (Table VI).

A comparison of the level of patient's satisfaction with perioperative pain treatment during the first 24 hours after surgery revealed a statistically significant difference between the groups $(\mathrm{p}=0.018)$. Fifty patients $(89.3 \%)$ in the Lorazepam group and 17 patients $(30.4 \%)$ in the placebo group rated their postoperative pain relief as good and excellent (satisfactory).

Six patients $(10.7 \%)$ in the anxiolysis group and thirty-nine $(69.6 \%)$ in the placebo group rated their pain relief as poor and fair (non satisfactory) (Table VII). The incidence of hypotension and bradycardia were similar in both groups $(p>0.05)$. However the significant side effects were drowsiness $(\mathrm{p}=0.001)$ and nausea / vomiting $(\mathrm{p}=0.027)$ which occurred in 12 and 6 patients respectively who received Lorazepam compared with the placebo group. Table III also shows the treatment of the complications.

Table-I: Demographic characteristics of the patients $(n=112)$

\begin{tabular}{|l|l|l|l|}
\hline Characteristics & $\begin{array}{c}\text { Anxiolysis(n=56) } \\
(\text { Mean } \pm \text { SD) }\end{array}$ & $\begin{array}{c}\text { Placebo }(\mathbf{n = 5 6}) \\
(\text { Mean } \pm \text { SD) }\end{array}$ & P value \\
\hline Age at last birthday (years) & $32.1 \pm 11.6$ & $31.5 \pm 9.5$ & 0.936 \\
\hline Height (cm) & $158.2 \pm 6.7$ & $157.3 \pm 5.1$ & 0.981 \\
\hline Sex (M:F) & $42: 14$ & $30: 26$ & 0.029 \\
\hline ASA physical status (I:II) & $20: 36$ & $24: 32$ & 0.562 \\
\hline
\end{tabular}

SD: standard deviation; M: male; F: female. ASA: American Society of Anesthesiologists.

Table-II: Indications for surgery in the two groups

\begin{tabular}{|l|l|l|l|l|}
\hline Surgical diagnosis & $\begin{array}{l}\text { Anxiolysis } \\
\mathbf{n}(\boldsymbol{\%})\end{array}$ & $\begin{array}{l}\text { Placebo } \\
\mathbf{n}(\boldsymbol{\%})\end{array}$ & $\begin{array}{l}\text { Total } \\
\mathbf{n}(\%)\end{array}$ & p-Value \\
\hline Femoral fractures & $34(60.7)$ & $32(57.1)$ & $66(58.9)$ & 0.878 \\
\hline Tibial fractures & $12(21.4)$ & $16(28.6)$ & $28(25.0)$ & 0.533 \\
\hline Tibio-femoral fractures & $10(17.9)$ & $6(10.7)$ & $16(14.3)$ & 0.428 \\
\hline Soft tissue & $0(0.0)$ & $2(3.6)$ & $2(1.8)$ & 0.496 \\
\hline
\end{tabular}

Table-III: Intraoperative clinical variables 
Felicia Dele Asudoet al.;EAS J OrthopPhysiother; Vol-2, Iss-5 (Nov-Dec, 2020): 47-56

\begin{tabular}{|l|l|l|l|}
\hline Characteristics & $\begin{array}{l}\text { Anxiolysis } \\
(\text { Mean } \pm \text { SD) }\end{array}$ & $\begin{array}{l}\text { Placebo } \\
\text { (Mean } \pm \text { SD) }\end{array}$ & P value \\
\hline Anaesthesia duration (min) & $144.9 \pm 26.0$ & $148.1 \pm 27.1$ & 0.939 \\
\hline Surgery duration (min) & $122.6 \pm 21.7$ & $127.7 \pm 25.6$ & 0.899 \\
\hline Fluid use , NS (L) & $2.2 \pm 0.6$ & $2.1 \pm 0.5$ & 0.888 \\
\hline Blood loss (L) & $0.6 \pm 0.4$ & $0.7 \pm 0.4$ & 0.609 \\
\hline Urine output (ml) & $87.0 \pm 19.4$ & $82.7 \pm 13.2$ & 0.735 \\
\hline Intra-op blood transfusion & $250.0 \pm 55.0$ & $280.0 \pm 30.0$ & 0.308 \\
\hline Intra-op doses of Ephedrine (n) (mg)** & $6(64)$ & $6(48)$ & 0.155 \\
\hline Atropine(n) (mg)** & $3(1.8)$ & $2(1.2)$ & 0.141 \\
\hline Metoclopromide* (n) (mg) & $6(60)$ & $0(0)$ & 0.027 \\
\hline
\end{tabular}

$\mathrm{n}$ - number of patient; mg- milligram; **-total dose; *-before induction of anaesthesia

Table-IV: Preoperative state anxiety

\begin{tabular}{|c|c|c|c|}
\hline State anxiety level & $\begin{array}{l}\text { Anxiolysis (Mean } \pm \text { SD) } \\
\text { n( \%) }\end{array}$ & $\begin{array}{l}\text { Placebo }(\text { Mean } \pm \text { SD }) \\
\text { n( \%) }\end{array}$ & $P$ value \\
\hline $\begin{array}{l}\text { Low } \\
\text { ( STAI 20-37) } \\
36(32.1)\end{array}$ & $\begin{array}{l}30.9 \pm 2.9 \\
16(28.6)\end{array}$ & $\begin{array}{l}33.6 \pm 2.7 \\
20(35.8)\end{array}$ & 0.643 \\
\hline $\begin{array}{l}\text { Moderate } \\
\text { (STAI 38-44) } \\
30(26.8)\end{array}$ & $\begin{array}{l}40.7 \pm 1.7 \\
12(21.4)\end{array}$ & $\begin{array}{l}39.6 \pm 1.4 \\
18(32.1)\end{array}$ & 0.510 \\
\hline $\begin{array}{l}\text { High } \\
\text { (STAI } 45-80) \\
46(41.1)\end{array}$ & $\begin{array}{l}46.1 \pm 4.8 \\
28(50.0)\end{array}$ & $\begin{array}{l}44.9 \pm 5.1 \\
18(32.1)\end{array}$ & 0.687 \\
\hline Mean score & $39.2 \pm 3.0$ & $38.1 \pm 3.2$ & 0.659 \\
\hline
\end{tabular}

Values are mean (SD) or frequency $(\mathrm{n}=112)$

Table-V: Incidence of moderate to severe postoperative pain among patients with moderate to high postoperative state anxiety

\begin{tabular}{|l|l|l|}
\hline Groups & $\begin{array}{l}\text { Moderate to high } \\
\text { anxiety }(\text { STAI } \geq \mathbf{3 8})\end{array}$ & $\begin{array}{l}\text { Moderate to severe pain } \\
(\mathbf{V A S}>\mathbf{3}) \mathbf{n}(\mathbf{\%})\end{array}$ \\
\hline $\begin{array}{l}\text { 6h post op } \\
\text { Placebo }\end{array}$ & $\mathbf{5 0}$ & $\mathbf{4 2}(\mathbf{8 4 . 0})$ \\
Anxiolysis & $\mathbf{2 6}$ & $\mathbf{1 0}(\mathbf{3 8 . 5})$ \\
\hline 12h post op & & $\mathbf{3 5}(\mathbf{7 6 . 1})$ \\
Placebo & $\mathbf{4 6}$ & $\mathbf{8}(\mathbf{3 3 . 3})$ \\
Anxiolysis & $\mathbf{2 4}$ & $\mathbf{2 6}(\mathbf{7 2 . 2})$ \\
\hline 18h post op & & $\mathbf{9}(\mathbf{3 7 . 5})$ \\
Placebo & $\mathbf{3 6}$ & $\mathbf{1 7}(\mathbf{7 3 . 9})$ \\
Anxiolysis & $\mathbf{2 4}$ & $\mathbf{6}(\mathbf{2 8 . 6})$ \\
\hline 24h post op & & \\
Placebo & $\mathbf{2 3}$ & $\mathbf{2 1}$ \\
Anxiolysis & \multicolumn{2}{|l}{} \\
\hline
\end{tabular}

Table-VI: Postoperative Morphine requirement over time

\begin{tabular}{|l|l|l|l|}
\hline Time point & Anxiolysis (Mean \pm SD) & Placebo (Mean \pm SD) & P value \\
\hline $6 \mathrm{~h}$ & $2.75 \pm 0.89$ & $4.70 \pm 0.01$ & 0.031 \\
\hline $12 \mathrm{~h}$ & $2.20 \pm 0.50$ & $4.05 \pm 0.14$ & 0.048 \\
\hline $18 \mathrm{~h}$ & $1.95 \pm 1.15$ & $3.35 \pm 1.23$ & 0.053 \\
\hline $24 \mathrm{~h}$ & $1.30 \pm 0.73$ & $2.70 \pm 1.14$ & 0.059 \\
\hline Total Bupivacaine required & $8.20 \pm 1.91$ & $14.8 \pm 2.10$ & 0.036 \\
\hline
\end{tabular}

h- hour

Table-VII: Patients assessment of satisfaction with pain relief 


\begin{tabular}{|l|l|l|l|}
\hline Groups & $\begin{array}{l}\text { Anxiolysis } \\
\mathbf{n}(\boldsymbol{\%})\end{array}$ & $\begin{array}{l}\text { Placebo } \\
\mathbf{n}(\boldsymbol{\%})\end{array}$ & p value \\
\hline Satisfaction & $50(89.3)$ & $17(30.4)$ & \multirow{2}{*}{0.018} \\
\hline No satisfaction & $6(10.7)$ & $39(69.6)$ & \\
\hline
\end{tabular}

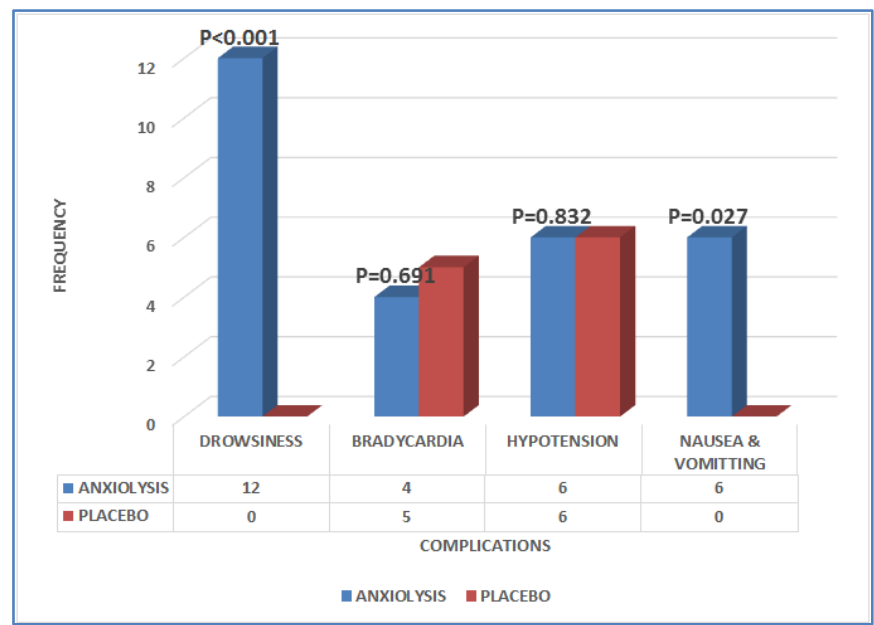

Fig-1: Complications reported in both groups.

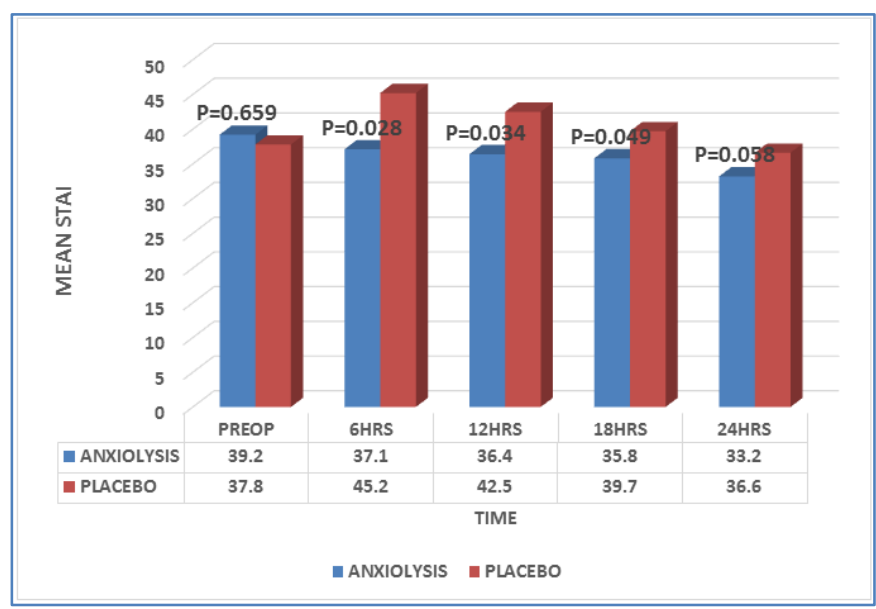

Fig-2: Anxiety scores reported on State-Trait Anxiety Inventory (STAI). Data are presented as mean (SD)

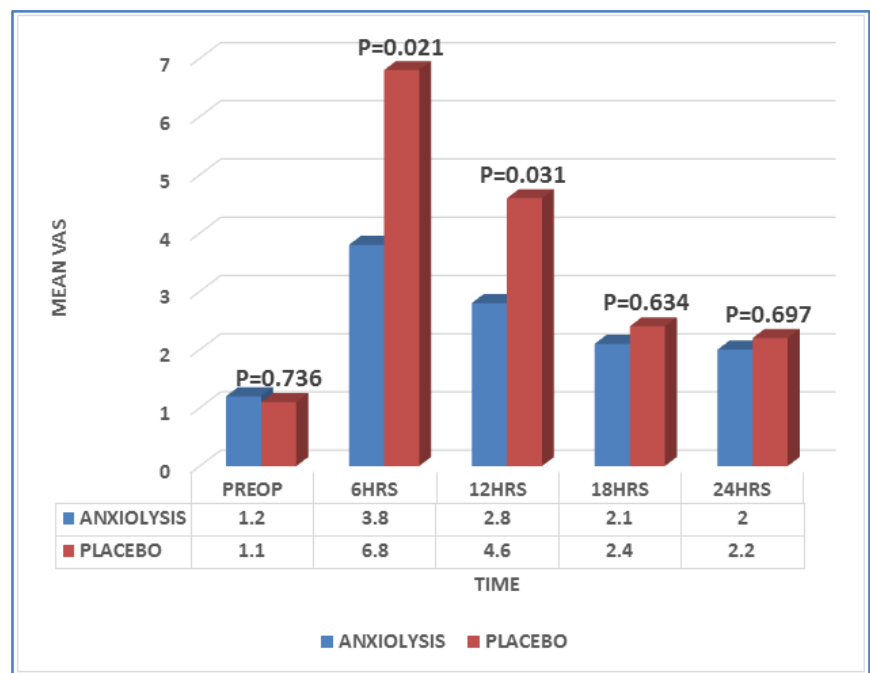

Fig-3: Pain scores reported on Visual Analog Scale (VAS). Data are represented as mean (SD) 


\section{DISCUSSION}

This study was carried out to assess the effect of preoperative Lorazepam on postoperative pain response on orthopaedic patients. The study shows that preoperative Lorazepam provides a significant reduction in postoperative state anxiety and pain, bupivacaine-morphine requirement and a better satisfaction with pain control. In addition, the malefemale ratio was significantly higher in the anxiolysis group than the study group. In the Lorazepam group significant side effects of drowsiness and nausea and vomiting (which necessitated the use of antiemetics) were reported compared to the group that received placebo as premedication.

The magnitude of the Lorazepam effect on postoperative pain was clinically relevant. The findings in this study indicate that the use of anxiolysis ameliorates postoperative pain. Patients who received Lorazepam preoperatively reported a significantly better postoperative pain scores than the placebo group as measured by VAS at $6 \mathrm{~h}(3.8 \mathrm{vs} 6.8)$ and $12 \mathrm{~h}(2.8 \mathrm{vs}$ 4.6). The clinical relevance of the anxiolysis was observed especially in the subgroup with moderate to high anxiety scores that presented an incidence of moderate to intense post-operative pain markedly lower than the placebo during the first $24 \mathrm{~h}$ of postoperative pain measurements. This effect on pain response was also evidenced by a significant reduction in the morphine utilization in the first $12 \mathrm{~h}$ and cumulative morphine utilization over first $24 \mathrm{~h}$. The anxiolytic effect of Lorazepam resulted in reduced postoperative analgesic consumption by more than $50 \%$.

The study also showed a gradual reduction in postoperative state anxiety, postoperative pain and bupivacaine utilization over $24 \mathrm{~h}$ after surgery independent of treatment group. The benefits of these interventions were statistically significant to induce anxiolysis and analgesia in the postoperative period. The study further revealed that about $30.4 \%$ and $89.3 \%$ of patients considered their pain control as satisfactory in the placebo and anxiolysis groups respectively. Although 12 and 8 patients experienced drowsiness and nausea or vomiting in the patients that received Lorazepam.

In this study, subjects in the treatment group reported a greater reduction in postoperative state anxiety in the first 18 hours. This finding is similar to the findings of Kainet al [14], to an extent. They identified reduced anxiety in the group treated with midazolam throughout the first postoperative month unlike our finding in which the beneficial effects of anxiolysis was lost by the $24^{\text {th }}$ hour postoperatively. The effect of benzodiazepine on anxiety appears to depend on the level of distress (depression, anxiety) exhibited by the patient prior to surgery [15].The study by Kain et al [14], was carried out on subjects for minor surgeries, thus, it can be assumed that the anxiety level of our subjects would be higher if compared with that of patients undergoing minor inpatient surgery or day case surgery. More so, orthopaedic patients have been found to have persistently raised anxiety score, presumably because of the anxiety provoking effects of plaster cast and other methods of immobilization [16]. Reducing anxiety has a number of physiological and psychological benefits. These include, improve perioperative cardiovascular parameters, better patient satisfaction with perioperative treatment, improved surgical outcome, shortened hospital stay and minimized lifestyle disruption [17]. Various pharmacological and non-pharmacological regimens to reduce perioperative anxiety have been devised $[6,17]$. Attenuation of the preoperative stress response results in improved postoperative outcome. In contrast the study by Caumo et al [4], reported no significant difference in the postoperative state anxiety in the diazepam and placebo groups in women undergoing total abdominal hysterectomy. Diazepam in doses used in that study did not produce a higher anxiolytic effect compared to the placebo. This may be related to the higher sedation reported in the intervention group. The use of continuous intravenous infusion of high dosage of propofol and fentanyl as reported in their study coupled with the prolonged sedative effect of diazepam and its metabolite may explain the insignificant effect on postoperative state anxiety.

Several studies $[5,13,17,18]$ have implicated anxiety as an important predictor of postoperative pain. Patients with high levels of preoperative state anxiety are particularly vulnerable to severe pain after surgery [16]. Pain leads to increased anxiety and anxiety leads to increased pain, thus, the optimal management of postoperative pain requires attention to the anxiety that surgical patients experience [19]. Likewise, in this study subjects receiving Lorazepam showed significantly lower postoperative pain score and morphine requirement in the first $12 \mathrm{~h}$, but not in placebo treated patients. The findings are consistent with that of Ciccozzi et al [20], who observed the influence of preoperative Lorazepam on postoperative pain control in women undergoing abdominal hysterectomy. The authors reported a significant reduction in postoperative pain response measured by pain score and morphine consumption during the first 12h. The study by Ciccozzi and colleagues has comparable methods. The same anxiolytic drug with similar doses and similar timing of administration was used in both studies. The technique of anaesthesia was neuraxial block in both studies. One explanation to these findings is that if we consider that perioperative stress is determined by pre and postoperative anxiety, it is possible that placebo treated patients had higher rates of moderate to severe postoperative pain because of increased anxiety levels throughout the postoperative period, while the anxiolytic effect of Lorazepam attenuates the pain perception. Secondly, the kind of anaesthesia is an important risk factor to postoperative 
anxiety and pain [3,20]. Neuraxial blockade protects patients from postoperative anxiety and produces prolonged inhibition of central nervous sensitization to intense postoperative pain [20].

The potential effect of benzodiazepine on analgesics is not limited to regional anaesthesia. Kain $e t$ al[14], also demonstrated that preoperative intramuscular midazolam significantly reduced the postoperative pain in outpatients who had surgeries under general anaesthesia. Benzodiazepine was used in both their study (midazolam) and our study (Lorazepam). Despite the fact that midazolam has a shorter duration of action, subjects that received it reported a greater reduction in pain throughout the first postoperative week. The result could also be attributed to the fact that the procedure resulted in lower psychological and physiological stress response thereby producing less impact on postoperative pain response.

On the other hand, Caumo et al, [4] reported contrasting findings in their study on the effect of preoperative anxiolysis on postoperative pain in patients undergoing total abdominal hysterectomy. They found that postoperative pain scores were significantly higher in diazepam group compared with the placebo and that morphine consumption with time did not change in both groups. The study further stated that patient received oral diazepam $10 \mathrm{mg}$ or placebo the night before surgery and $1 \mathrm{~h}$ prior to start of anaesthesia. Also a continuous infusion of propofol $(0.08-0.1 \mathrm{mg} / \mathrm{kg} / \mathrm{min})$ was administered to maintain conscious sedation during the surgery. The different result from this present study may be explained by the excessive sedation experienced in the intervention group. The prolonged sedative effect of diazepam and its metabolites coupled with the high dosage of propofol could hinder the cooperation and judgment of patients in the treatment group. In addition the oversedation could have masked the benefits of preoperative anxiolytic drug in the short-term. Despite the anaesthetic technique of combined spinal epidural used in both groups, the clinical relevance of the anxiolysis was evident by the substantial difference in satisfaction score with pain control. More patients in the anxiolysis group rated their pain relief as good and excellent (satisfactory) compared with placebo $(89.3 \%$ vs $30.4 \%, p=0.018$ ) which was statistically significant. Ciccozzi et al [20], were unable to establish a significant difference in the satisfaction with pain control among the groups that received Lorazepam and placebo. This may be attributed to the choice of anaesthesia and postoperative pain management. Ciccozzi and colleagues [20], used subarachnoid block for the surgery and intravenous patient-controlled analgesia (IV PCA) for the postoperative pain. However our study used CSE and PCEA for postoperative pain which is superior. The study by Lee et al [21], showed that epidural PCA had a superior postoperative pain control after 6 hours of surgery to IV PCA in patients that had lumbar surgeries.
Regarding the side effects, Lorazepam showed a significant increase in the number of side effects compared with the placebo patients. Drowsiness and nausea and vomiting were reported in 12 and 6 patients respectively. These are well recognized complications of benzodiazepines in previous studies [12, 22, 23]. Hargreaves et al [23], reported significant side effect of nausea and dizziness in day-case patients premedicated with oral midazolam and temazepam compared to placebo. In addition, the nausea and vomiting in this study occurred only before the induction of anaesthesia and was not related to the subarachnoid block. This study showed there was a male predominance and male to female ratio was significantly higher in the anxiolysis group. Multiple randomization of the study population would have eliminated the imbalance in sex distribution. However, this finding is not uncommon as there are more men at risk of trauma and fracture than women due to greater exposure to driving, alcohol, drugs and other outdoor activities [24, 25].

There are several methodological issues regarding the design of this study that should be mentioned. In other to minimize all possible confounding variables, great attempt was made to have a well-controlled quantitative study (only lower limb orthopaedic surgeries, exclusion criteria, standardization of anaesthetic technique and postoperative pain control treatment) so as to maintain consistency. The study also employed validated tool for the evaluation of anxiety -STAI- which is the gold standard and widely used in studies published in peerreviewed literature [1, 23]. Patient's level of anxiety and pain were also assessed preoperatively to obtain a baseline value for comparison and help diminish selfreporting bias. A large study sample was used to ensure data reliability.

\section{CONCLUSION}

In conclusion, this randomized controlled double blind study designed to determine the anxiolytic effect of Lorazepam on postoperative pain response in major lower limb orthopaedic surgeries shows that preoperative anxiolysis reduces postoperative pain perception, analgesic requirement, postoperative anxiety and gives a better satisfaction with pain control in this population. Therefore premedication with benzodiazepines should be implemented in this population especially in those identified with raised preoperative state anxiety in order to decrease postoperative pain in conjunction with analgesics consumption. It is suggested therefore, that Lorazepam should be a good anxiolytic in the hands of anaesthetists attending to patients for orthopaedic procedures.

\section{REFERENCES}

1. Kain, Z.N., Mayes, L.C., Cicchetti, D.V., Bagnall, A.L., Finley, J.D., \& Hofstadter, M.B. (1997). The Yale preoperative anxiety scale: How does it 
compare with a "gold standard"? AnesthAnalg, 85, 783-88.

2. Akanidomo, J.I., \& Hannah, B.I. (2011). Psychological issues in paediatric surgery. In Emmanuel A.A. ( ${ }^{\text {st }}$ ed. $)$, Paediatric surgery: A comprehensive text for Africa, Global HELP Organization, Seattle, Washington, pp. 82-89.

3. Caumo, W., Schmidt, A.P., Schneider, C.N., Bergmann, J., Iwamoto, C.W., \&Adamatti, L.C. (2001). Risk factors for postoperative anxiety in adults. Anaesthesia, 56(8), 720-28.

4. Caumo, W., Hidalgo, M.P., Schmidt, A.P., Iwamoto, C.W., Adamatti, L.C., \& Bergmann, J. (2002). Effect of preoperative anxiolysis on postoperative pain response in patients undergoing total abdominal hysterectomy. Anaesthesia, 57(8), 740- 46.

5. Kain, Z.N., Sevarino, F., Alexander, G.M., Pincus, S., \& Mayes, L.C. (2000). Preoperative anxiety and postoperative pain in women undergoing hysterectomy. A repeated-measures design. J Psychosom Res, 49, 417-22.

6. Mokhuane E.Q. (2011). The effect of mood on postoperative pain and the reliability and validity of the Wisconsin brief pain questionnaire adapted on black South Africans. J NeurolNeurophysiol, 2(1), 3.

7. Mads, U.W., Helena, N.M., Nielsen, P.R., \&Rudin, A. (2010). Prediction of postoperative pain; A systematic review of predictive experimental pain studies. Anesthesiology, 112, 1494-502.

8. Christopher, L.W., \&Srinivasa, N.R. (2011). Treatment of acute postoperative pain.www.the lancet.com, 377, 2215- 25.

9. Apfelbaum, J.L., Chen, C., Mehta, S.S., \&Gan, T.J. (2003). Postoperative pain experience: Result from a national survey suggest postoperative pain continues to be undermined. AnesthAnalg, 97(2), $534-40$.

10. Masigati, H.G., \&Chilonga, K.S. (2014). Postoperative pain management outcomes among adults treated at a tertiary hospital in Moshi, Tanzania. Tanzania Journal of Health Research, 16(1). unpaginated.

9. Kolawole, I.K., \&Fawole, A.A. (2003). Postoperative pain management following caesarean section in University of Ilorin Teaching Hospital (UITH), Ilorin, Nigeria. West Afr J Med, 22(4), 305-9.

10. Karim, M.E., Rahman, M.H., Hossain, M.H., \&Ahsan, M.N. (2011). Lorazepam as anxiolytic sedative night before operation. Journal of Armed Forces Medical College Bangladesh, 7(2), 25-28.

11. Hui, Y.V., Amir, A., Peng, W.H., Wong, J., \& Chung, F. (2009). Predictors of postoperative pain and analgesic consumption: A qualitative systemic review. Anesthesiology, 111(3), 657 -77.

12. Kain, Z.N., Sevarino, F., Pincus, S., Alexander, G.M., Wang, S.M., \&Ayoub, C. (2000). Attenuation of preoperative stress response with midazolam: effects on postoperative outcome. Anesthesiology,93(1), $141-47$.

13. Egan, K.J., Ready, L.B., Nessly, M., \& Greer, B.E. (1992). Self-administration of midazolam for postoperative anxiety: a double blinded study. Pain, 49, 3-8.

14. Feinmann, C., Ong, M., Harvey, W., \& Harris, M. (1987). Psychological factors influencing postoperative pain and analgesic consumption. $\mathrm{Br} J$ Oral Maxillofac surgery, 25(4), 285-92.

15. Jlala, H.A., French, J.L., Foxall, G.L., Hardman, J.G., \&Bedforth, N.M. (2010). Effect of multimedia information on perioperative anxiety in patients undergoing procedures under regional anaesthesia. Br J Anaesth, 104, 369 -74.

16. Nelson, F.V., Zimmerman, L., Barnason, S., Nieveen, J., \&Schmaderer, M. (1988). The relationship and influence of anxiety on postoperative pain in the coronary artery bypass graft patient. J Pain symptom manage, 15(2), 10209.

17. Punjabi, I., Waqar-ul-Nisa, A., Farooqi, A., Ahmad, A., \&Magbool, A. (2013). Effect of intrathecal midazolam on quality and duration of spinal anaesthesia with bupivacaine in perineal and lower limb surgery. The Internet Journal of Anesthesiology, 32(1).

18. Ciccozzi, A., Marinangeli, F., Colangeli, A., Antonacci, S., Pilerci, G., Di Stefano, L., \&Varrassi, G. (2007). Anxiolysis and postoperative pain in patients undergoing spinal anesthesia for abdominal hysterectomy. Minerva anestesiologica, 73(7-8), 387-394.

19. Lee, S. H., Kim, K. H., Cheong, S. M., Kim, S., Kooh, M., \& Chin, D. K. (2011). A comparison of the effect of epidural patient-controlled analgesia with intravenous patient-controlled analgesia on pain control after posterior lumbar instrumented fusion. Journal of Korean Neurosurgical Society, 50(3), 205.

20. Jakobsen, C. J., Blom, L., Brondbjerg, M., \&Lenler-Petersen, P. (1990). Effect of metoprolol and diazepam on pre-operative anxiety. Anaesthesia, 45(1), 40-43.

21. Hargreaves, J. (1988). Benzodiazepine premedication in minor day-case surgery: comparison of oral midazolam and temazepam with placebo. British Journal of Anaesthesia, 61(5), 611-616.

22. Pathak, S. M., Jindal, A. K., Verma, A. K., \&Mahen, A. (2014). An epidemiological study of road traffic accident cases admitted in a tertiary care hospital. Medical journal armed forces India, 70(1), 32-35.

23. Singer, B. R., McLauchlan, G. J., Robinson, C. M., \& Christie, J. (1998). Epidemiology of fractures in 15000 adults: the influence of age and gender. The Journal of bone and joint surgery. British volume, 80(2), 243-248. 


\section{APPENDIX I}

ASSESSMENT OF ANXIETY (THE STAI FORM)

Your responses will be treated completely confidentially, and results will only be referred to in statistical form or anonymously. Please read the following statements about how people feel in general. Circle the number that best describes how you generally feel. There is no right or wrong answers.Each of the 20 items is a statement rated in a four-point scale with responses being either 1 (Not at all), 2(somewhat / mildly so), 3(moderately so), or 4 (very much so).

1.) I feel calm

[1] [2] [3] [4]

2.) I feel secured

[1] [2] [3] [4]

3.) I am tense

[1] [2] [3] [4]

4.) I feel strained

[1] [ 2] [3] [4]

5.) I feel at ease

[1] [2] [3] [4]

6.) I feel upset

[1] [2] [3] [4]

7.) I am presently worrying over misfortune [2] [3] [4]
8.) I feel satisfied
[1] [2] [3] [4]
9.) I feel frightened
[1] [2] [3] [4]

10.) I feel comfortable

[1] [2] [3] [4]

11) I feel self- confident

[1] [2] [3] [4]

12.) I feel nervous

[1] [2] [3] [4]

13.) 1 am jittery

[1] [2] [3] [4]

14.) 1 feel indecisive

[1] [2] [3] [4]

15.) I am relaxed

[1] [2] [3] [4]

16.) I feel content

[1] [2] [3] [4]

17.) I am worried

[1] [2] [3] [4]

18.) I feel confused

[1] [2] [3] [4]

19.) I feel steady

[1] [2] [3] [4]

20.) I feel pleasant

\section{APPENDIX II}

\section{MEASUREMENT OF PAIN (VAS SCALE)}

The visual analog scale is one of the most commonly used measures of pain intensity in pain research. The far left end indicates 'No pain' and the far right end indicates 'Worst pain ever'. Indicate how much pain you are currently feeling by marking $(\mathrm{X})$ at the point on the line between the faces.

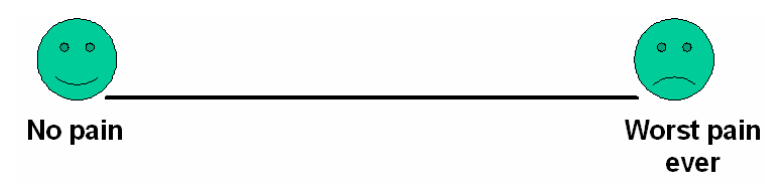

\section{APPENDIX III}

DATA COLLECTION FORM

1. Randomization NO

2. Date

3. Hosp. No-

4. Age

5. Gender

6. Height

7. Weight

8. Diagnosis-

9. Surgical procedure

10. Duration of Surgery

a) Time of surgical incision

b) Time of last stitch

11. Duration of Anaesthesia

a) Time of deposit of the local anaesthetic into the subarachnoid space

b) Time of last stitch

\section{APPENDIX IV}

\section{ASSESSMENT OF PATIENT'S}

SATISFACTION

Tick one of the boxes below that best describes your satisfaction with pain relief.
[0] POOR
[1] FAIR
[2] GOOD
[ 3 ] EXCELLENT 